\title{
HISTÓRIA DAS MULHERES E HISTÓRIA PÚBLICA: DESAFIOS E POTENCIALIDADES DE UM ENSINO POSICIONADO
}

\section{HISTORY OF WOMEN AND PUBLIC HISTORY: CHALLENGES AND POTENTIALITIES OF POSITIONED EDUCATION}

\author{
Marta Gouveia de Oliveira Rovai ${ }^{1}$ \\ Lívia Nascimento Monteiro ${ }^{2}$
}

\begin{abstract}
Resumo
O texto apresenta uma discussão sobre as possibilidades do ensino de história das mulheres, em sua relação com a história pública e com o cenário conflituoso de avanços e opressões sobre o gênero feminino, no Brasil. Acreditamos que o ensino de história possa promover processos posicionados no reconhecimento das histórias das mulheres, questionando narrativas históricas pretensamente neutras. Para isso, propomos algumas práticas, fazendo uso de narrativas biográficas ou autobiográficas femininas (individuais ou em rede) e de tecnologias diversas, para facilitar o acesso, a análise, a produção e o compartilhamento do conhecimento histórico, a partir de demandas do presente e do diálogo com diferentes públicos, dentro e fora da sala de aula.
\end{abstract}

Palavras-chave: desigualdade de gênero, ensino de história, história pública, história das mulheres.

\begin{abstract}
:
The text presents a discussion about the possibilities of teaching women's history, in its relationship with public history and with the conflicting scenario of advances and oppressions about the female gender, in Brazil. We believe that history teaching can promote processes positioned in the recognition of the history of women, questioning allegedly neutral historical narratives. For this, we propose some practices, using female biographical or autobiographical narratives (individuals or networks) and different technologies, to facilitate access, analysis, production and sharing of historical knowledge, based on the demands of the present and dialogue with different public, inside and outside the classroom.
\end{abstract}

Keywords: gender inequality, history teaching, public history, women's history.

\footnotetext{
1 Professora Adjunta da Universidade Federal de Alfenas (UNIFAL-MG). Doutora em HIstória Social pela Universidade de São Paulo (USP), com pós-doutamento pela UFF/RJ. Mestra pela Pontifícia Universidade Católica (PUC/SP).Coordenadora do Grupo de Pesquisa História do Brasil e do Grupo de Estudos História Oral, gênero e diversidade. Pesquisadora do Núcleo de Estudos em História Oral (NEHO/USP) e do Formatio (UNIFAL). Trabalha com os temas: História Pública; história oral, gênero e ensino de história.

2 Doutora em História pela Universidade Federal Fluminense, Mestre em História Social pela Universidade Federal do Rio de Janeiro e graduada em História pela Universidade Federal de Juiz de Fora. Professora Adjunta de Laboratório do Ensino de História e Supervisora do Estágio obrigatório na Universidade Federal de Alfenas - UNIFAL. Professora Colaboradora no ProfHistória - Programa de Mestrado Profissional em Ensino de História na Universidade Federal Fluminense. Participa do grupo de pesquisa Cultna - Grupo de Estudo e Pesquisa Cultura Negra no Atlântico - coordenado pela profa. dra. Martha Abreu e do GT Emancipações e Pós-Abolição da ANPUH. Produtora e roteirista do documentário "Dos Grilhões aos Guizos. Festa de maio e as narrativas do passado", fruto de sua tese de doutorado, em parceria com a Narre Produções e a Associação de Congada e Moçambique de Piedade do Rio Grande-MG.
} 


\section{HISTÓRIA}

\section{Dossiê: Ensino de História, História das Mulheres e Desigualdades Sociais no Brasil}

No final de 2019, o Núcleo de Atenção à Mulher, da Universidade Federal de Alfenas, organizou atividades para a Campanha 16 dias de Ativismo pelo Fim da Violência contra as Mulheres ${ }^{3}$. Entre as diversas atividades desenvolvidas, houve uma roda de conversa com mulheres negras e LGBTQIA $+^{4}$, da qual participou a agente de saúde e mulher trans, Wall Alves. A forma como ela chegou e a sua presença no auditório já demonstrava que um grande evento aconteceria naquela noite. De salto alto, batom, perfume e com postura elegante e altiva, de quem estava ali para narrar suas próprias histórias, sem cortes e imposições, ela manteve a atenção da plateia e a emocionou.

Wal narrou suas dores, violências, trajetória e luta. Apresentou-nos dados impactantes e contou sobre o cotidiano dilacerante que enfrenta como mulher trans. Ela falou também sobre amores, amizades, afetos e encontros. A plateia, composta majoritariamente por estudantes de diversos cursos da graduação - especialmente da área da Saúde - ouvia em silêncio e impactada com a narrativa chocante sobre os casos de violência transfóbica, denunciadas de modo tão firme por ela, que encarava a todos e todas.

Junto dela, duas estudantes, Juliana, bissexual, e Ana, uma jovem negra hetero, tornavam públicas as suas trajetórias de conquistas, mas também de preconceitos, chamando a atenção para a diversidade e interseccionalidades de experiências (DAVIS, 2016) que precisam ser conhecidas para descolonizar narrativas eurocentradas, androcêntricas e heterocisnormativas que compõem currículos, fontes e materiais didáticos ${ }^{5}$. Ao final das falas, um aluno, emocionado e sem conseguir segurar as lágrimas, confidenciou-nos que aquele momento teria sido

\footnotetext{
3 O Núcleo de Atenção à Mulher faz parte do Departamento de Direitos Humanos, da Universidade. A campanha é anual, internacional e nacional, e a mobilização abrange o período de 20 de novembro a 10 de dezembro. Ela procura mobilizar indivíduos e organizações para engajamento na prevenção e na eliminação da violência contra as mulheres e meninas. Mais informações, no site: http://www.onumulheres.org.br/16dias/ - Acesso em 11 nov 2019.

${ }^{4}$ A sigla LGBTQIA+ refere-se à orientação sexual (lésbica, gays e bissexuais) e às identidades de gênero (transexuais, travestis e transgêneros, queer, intersexuais e assexuais, entre tantas outras mais).

5 Optamos aqui por usar o termo descolonizar, utilizado por Nilma Lima Gomes, para quem a descolonização dos currículos implica conflito, confronto de experiências históricas, negociações e a produção de algo novo, superando a perspectiva eurocêntrica de conhecimento e de mundo, desnaturalizando e colocando em evidência as construções históricas das diferenças culturais e sociais entre grupos humanos (GOMES, 2012, p.7).
} 


\section{HISTÓRIA}

Dossiê: Ensino de História, História das Mulheres e Desigualdades Sociais no Brasil

"a maior aula da sua vida" e que, daquele dia em diante, nunca mais conseguiria ver o mundo da mesma maneira preconceituosa que enxergava até então.

Os aprendizados daquela noite ainda ressoam em nós e a tentativa de expôlos nesse artigo tem como objetivo sensibilizar e propor, a partir dessa experiência e dos saberes daquelas mulheres (BONDÍA, 2002), caminhos possíveis para uma educação antissexista nos espaços educativos do país - sejam escolas, universidades, projetos e organizações diversas.

A defesa do ensino de História crítico e reflexivo já vem sendo realizada por diversos(as) especialistas do campo que propõem, cada vez mais, que as aulas de História sejam tomadas pelos(as) novos(as) sujeitos(as) e que as narrativas ainda não contadas na sala de aula sejam conhecidas e valorizadas (CIRCE, 2004; COSTA, 2010; PINSKY, 2013; LEITE, 2010; COLLING, TEDESCHI, 2015). Esse movimento tem encontrado terreno fértil, especialmente na última década, entre professores e professoras de História no país que buscam, em suas práticas pedagógicas, acionar e problematizar os chamados temas sensíveis (PEREIRA, SEFFNER, 2018) para dentro da sala de aula.

É válido pontuar que a história ensinada nas escolas esteve, por muito tempo, sendo narrada na perspectiva quase exclusivamente de personagens masculinos tratados como heróis e protagonistas das ações e eventos, mesmo quando se trata da resistência coletiva. Thais Fonseca (2006), ao ponderar sobre a história do ensino de História no Brasil, aponta que houve, por muito tempo, o império da memorização das datas, dos fatos e dos heróis, e podemos incluir aqui que, majoritariamente, esse império esteve dominado pelas figuras masculinas, brancas e heterocisgêneras, ignorando a pluralidade de experiências e colonizando o saber histórico.

O movimento de renovação historiográfica e do ensino de História, ocorrido a partir dos anos 1980 e 1990, no Brasil, marcou de forma sobremaneira as novas bases epistemológicas do ensinar história. Ancorados(as) e em diálogos com os movimentos sociais - como os movimentos negros, LGBTQIA+, feministas e de mulheres novos(as) sujeitos(as) demandavam que suas vozes fossem ouvidas e suas histórias contadas, inclusive por eles(as) mesmos(as). A busca pelo protagonismo e as disputas de narrativas impetraram novas propostas curriculares, com todas as ambivalências e contradições inerentes ao processo, como bem analisa Circe 


\title{
HISTÓRIA
}

Dossiê: Ensino de História, História das Mulheres e Desigualdades Sociais no Brasil

Bittencourt (2004). De maneira geral, o papel do(a) professor(a) de História passou a ser, cada vez mais, ligado às funções educativas que buscavam evitar a amnésia da sociedade. Sobre isso, ainda, Ana Maria Colling e LosandroTedeschi afirmam:

\begin{abstract}
A história das mulheres, ao colocar no centro a questão das relações entre os sexos, revisita um conjunto de problemas tão caros à historiografia - o poder, as representações, as imagens e o real, o social e o político, o pensamento simbólico, enfim a marginalização, o esquecimento de sujeitos na história do Ocidente. A dificuldade de sua história deve-se inicialmente ao apagamento de seus traços, tanto públicos quanto privados. A falta de informações contrasta com a abundância dos discursos e das imagens (musas e deusas). Fazer a história das mulheres é chocar-se contra esse bloco de representações que as cobre. (COLLING; TEDESCHI, 2015, p.311)
\end{abstract}

Mais recentemente, o movimento na historiografia brasileira e internacional vem produzindo importantes contribuições para a compreensão da necessidade de uma história pública e de novas possibilidades sugeridas aos(às) historiadores(as) que se entremearam por esse caminho de pesquisa e, também, de ensino (ALMEIDA, ROVAI, 2011; ALMEIDA, MAUAD, SANTHIAGO, 2016; LIDDINGTON, 2011). Temas como memórias em rede, demandas identitárias, lutas e experiências silenciadas, patrimônios difíceis e usos do passado, assim como a construção e divulgação de narrativas múltiplas pelo cinema, rádio, internet, literatura, exposições museológicas e outras dinâmicas, estão no escopo das pesquisas desse recente campo de atuação no Brasil, ampliando as perspectivas de produção científica no país e de uma plataforma de observação e de criação de cenários participativos e democráticos voltados à inclusão de diferente públicos nos processos de criação e de difusão do conhecimento histórico, com suportes em arquivos, museus, filmes, televisões, jornais, mídias eletrônicas e outros (CARVALHO, TEIXEIRA, 2019; FERREIRA, 2016; SANTHIAGO, 2016; 2018).

De acordo com a Rede Brasileira de História Pública, a "história pública, mediadora de saberes em diálogo e em conflito, é uma poderosa plataforma de observação e ação frente às múltiplas possibilidades de tomada de posse de experiência passada pelos coletivos que se formam nas trincheiras culturais (...)" (Rede Brasileira de História Pública, 2019). Entendida sob a perspectiva do ensino, a história pública não se reduziria à transposição de conhecimentos históricos 


\section{HISTÓRIA}

Dossiê: Ensino de História, História das Mulheres e Desigualdades Sociais no Brasil acadêmicos a um público passivo, em sala de aula. Pelo contrário, ela seria um posicionamento de observação e reconhecimento de múltiplas experiências, por parte de docentes e discentes, e um movimento de criação de dinâmicas participativas e dialógicas de acesso, de produção e de compartilhamento de múltiplos saberes, levando em conta as inúmeras tecnologias, os procedimentos e conceitos historiográficos e as múltiplas contribuições dos(as) sujeitos(as) no processo de ensino e aprendizagem.

Tomando essa concepção como suporte, apresentamos neste texto os desafios para o ensino de história das mulheres a partir das possibilidades apresentadas pela história pública e suas relações com narrativas biográficas e autobiográficas femininas. O trabalho colaborativo e as parcerias constituídas entre professores(as) e alunos(as), assim como entre os(as) alunos(as) e as personagens escolhidas para serem biografadas e autobiografadas pretendem desenvolver as práticas da história pública, alicerçadas pelos debates centrais do ensino de história, em profícuo diálogo com a historiografia acadêmica (ROCHA, MAGALHÃES, GONTIJO, 2009). Acreditamos ser este um dos vários caminhos para tentar tornar a escola e a sala de aula espaços para se pensar as demandas sociais, políticas e culturais do tempo presente, para compartilhar vivências, exercitar o diálogo e trabalhos colaborativos, pensar os usos do passado e entender as mais variadas tecnologias para a formação crítica dos cidadãos e das cidadãs como motores de mudanças quanto às relações desiguais de gênero.

Para isso, fazemos uma breve apresentação sobre o cenário de conquistas e de opressões que envolvem as trajetórias das mulheres no Brasil, com a finalidade de provocarmos reflexões acerca de como o debate sobre silenciamentos e desigualdades precisa ser abordado em sala de aula, também um espaço coletivo, sob a perspectiva da história pública. Ao final, pretendemos contribuir com a sugestão de possibilidades de trabalho que permitam conhecer e reconhecer as existências plurais de mulheres, rompendo com uma história linear, masculina, branca e heterocisgênera, sem ter a pretensão de apresentar modelos de atuação. 


\section{HISTÓRIA}

Dossiê: Ensino de História, História das Mulheres e Desigualdades Sociais no Brasil

Histórias de conquistas e violações das mulheres: um cenário ainda invisibilizado na escola

A história da participação de mulheres na vida pública e das relações de gênero na vida privada tem sido a história do desenvolvimento de relações de poder, hierárquicas e discriminatórias, pautadas pela divisão social por sexo, raça e classe, entre tantos outros marcadores transformados, muitas vezes, em estigmas para desqualificar e silenciar. Durante os muitos anos de nossa história, questões relacionadas às mulheres foram ignoradas ou tratadas como secundárias nos registros e no debate público, diante de ações masculinas, consideradas épicas e heroicas, mesmo quando relacionadas a movimentos coletivos de resistência.

Os dados mais sistematizados e a devida reflexão sobre a desigualdade de oportunidades na educação e no mercado de trabalho, assim como sobre as múltiplas formas de violência contra as mulheres, ainda são muito recentes no Brasil, frutos de lutas dos movimentos feministas, em constante confronto com grupos conservadores que insistem em restringir suas conquistas. Nos governos Temer e Bolsonaro, assistimos medidas de extinção de importantes órgãos de fomento e de implementação de políticas públicas para as mulheres, na contramão das pautas feministas. Na educação, a Base Nacional Comum Curricular (BNCC) teve excluídos os termos gênero e sexualidade, demonstrando com clareza o posicionamento reacionário de um discurso político que se apresenta como neutro, mas que pretende calar e evitar debates que questionem as estruturas de dominação de gênero.

Num país em que milhões de famílias brasileiras têm $92 \%$ da titularidade do Programa Bolsa Família em nome de mulheres (BARTHOLO; PASSOS; FONTOURA, 2017), dando a elas a autoridade de receber o benefício, mantém-se, ainda, a imagem tradicional da mulher como responsável pelo cuidado da família e dos afazeres domésticos e submetida aos mandos masculinos e a uma lei de maternidade que não atende à demanda por uma licença parental que dividia a responsabilidade pelos filhos com os homens. A ausência de discussões e de políticas públicas que evidenciem que questões como estas não devem ficar restritas ao privado, torna a vida da maioria das mulheres invisibilizadas. 


\section{HISTÓRIA}

Dossiê: Ensino de História, História das Mulheres e Desigualdades Sociais no Brasil

Além de muitas delas passarem a ser provedoras de suas famílias, nos últimos anos, também se tornaram maioria na educação. Os dados do censo escolar, do Instituto Nacional de Estudos e Pesquisas Educacionais Anísio Teixeira (INEP, 2019) $)^{6}$, mostram que elas representam $70,6 \%$ das matrículas nas licenciaturas, são $80 \%$ dos(as) gestores(as) escolares, $51 \%$ dos(as) estudantes no Ensino Médio e correspondem a $57 \%$ do total de ingressantes nos cursos de graduação, ocupando cursos que historicamente eram relacionados ao gênero masculino.

Todavia, as estatísticas não dão conta de refletir alterações na estrutura de dominação masculina e racista no mercado de trabalho, assim como nas salas de aula. Outros dados revelam a desigualdade que atravessa as relações de gênero no país, como o fato de que, mesmo com ensino superior, as mulheres recebam em média $47,24 \%$ a menos que os homens e que as mulheres negras ganhem menos do que as brancas (IBGE, 2018), isso agora agravado pela situação pandêmica em que vivemos. Na política, as eleições de 2018 demonstraram que elas conquistaram apenas $15 \%$ das cadeiras da Câmara Nacional dos deputados, com 77 mulheres eleitas, e somente $14,8 \%$ das cadeiras no Senado Federal, com 12 senadoras (BRASIL, 2018). Ainda é preciso lembrar que as parlamentares são, em sua maioria, brancas, católicas e com curso superior completo, não refletindo a diversidade de mulheres brasileiras, excluídas em sua maioria.

A presença das mulheres no mercado de trabalho, na educação e na política institucional, em geral, não é acompanhada por um discurso ou por práticas que defendam a igualdade de gênero ou a quebra nos padrões estabelecidos para a divisão sexual, de classe e racial. Muitas vezes, as oportunidades a elas não se dão em campos tradicionalmente masculinos e cria-se certa normalidade para a ocupação de espaços a partir da divisão por sexo. A naturalização dos papéis femininos e masculinos, opondo privado e público, passa também pelo entendimento do senso comum que aceita muitas das formas de violências existentes (físicas ou simbólicas) e busca torná-las justificáveis.

No Brasil, os índices levantados pelo Sistema de Ouvidoria Nacional de Direitos Humanos (BRASIL, 2019) apontaram que de janeiro a julho de 2019 o Programa Ligue

${ }^{6}$ Disponível em: http://portal.inep.gov.br/artigo/-/asset publisher/B4AQV9zFY7Bv/content/id/6842861 e http://inep.gov.br/artigo/-/asset publisher/B4AQV9zFY7Bv/content/mulheres-sao-maioria-no-ensinomedio-em-73-dos-municipios-brasileiros/21206 - Acesso em 13 jun 2020. 


\section{HISTÓRIA}

Dossiê: Ensino de História, História das Mulheres e Desigualdades Sociais no Brasil

180 registrou 46.510 denúncias de violência contra a mulher, entre elas ameaças (1.844), cárcere privado (1.243), feminicídio (36), tentativa de feminicídio (2.688), tráfico de mulheres (16), violência doméstica e familiar (35.769), violência física (1.1050), moral (1.921), obstétrica (116), sexual (1.109) e virtual (180). Quanto às mulheres transexuais, é preciso lembrar, ainda, da enorme violência praticada contra elas, cotidianamente, e enfatizar que as negras são as mais atingidas entre heteros e LGBTQIA+. Segundo o mapeamento realizado, sobre o ano de 2019, pela Associação Nacional de Travestis e Transexuais (ANTRA), o índice de violações aos Direitos Humanos de pessoas trans, no Brasil, foi considerado o maior do mundo:

Desde o primeiro ano em que o Brasil passou a constar no ranking mundial, houve um aumento em $114 \%$ no número de assassinatos de pessoas trans no país. O levantamento demonstra que as práticas policiais e judiciais caracterizam-se pela falta de rigor na investigação, identificação e prisão dos suspeitos. E em 2019 , apenas $8 \%$ dos casos tiveram os suspeitos identificados e $82 \%$ das vítimas eram negras. Pessoas trans do gênero feminino representam $97 \%$ dos casos e $64 \%$ dos assassinatos aconteceram nas ruas, assim como fica evidente que os assassinos não costumam ter relação direta, social ou afetiva com a vítima. [...] Em 2019, a região sudeste apresentou aumento de $10,8 \%$ no número de assassinatos de pessoas trans e a idade média das vítimas dos assassinatos em 2019 é de 29,7 anos. $91 \%$ dos casos reportados pela mídia expuseram o nome de registro das vítimas e muitos deles sem menção ao nome social. (BENEVIDES; NOGUEIRA, 2020)

Estas estatísticas, mais do que números frios, são apresentadas aqui para compreendermos que a participação feminina no mercado e nos espaços institucionais não é capaz de superar as desigualdades socialmente construídas e naturalizadas por um formato de educação que as ignora no cotidiano das escolas e na elaboração de seus currículos. São evidências que demonstram que, se há avanços em certos aspectos, ainda há uma cultura e uma estrutura patriarcal, excluidora e estigmatizante sobre as mulheres, que precisa ser combatida, passando por aquilo que se ensina ou se omite em sala de aula (apenas um dos aspectos a ser considerado aqui).

Guacira Louro (1997, p.88) nos ajuda a ponderar como a escola pode ser um espaço de reprodução das desigualdades de gênero e opressão, naturalizando segregações, silenciamentos e submissões. A autora contribui para pensarmos como 


\section{HISTÓRIA}

Dossiê: Ensino de História, História das Mulheres e Desigualdades Sociais no Brasil

as diferentes instituições e práticas sociais são constituídas pelos gêneros (que também os constituem). A escola, como uma delas, não somente fabrica os(as) sujeitos(a) como é por eles(as) engendrada, também por representações étnicas, religiosas, de classe etc. Se essas instituições têm gênero, classe e raça, a autora pergunta sobre qual seria o gênero da escola? Para ela, esta seria feminina porque é, primordialmente, um lugar de atuação de mulheres (como os dados nos mostram) e está configurada na forma como se organiza e nas funções que elas exercem. Mas a escola também é masculina, pois ali se lida, fundamentalmente, com o conhecimento que foi historicamente produzido pelos homens, os mesmos que também determinam lugares e narrativas, ao longo da história, que procuram obstruir as histórias femininas.

Levando isso em conta, Louro (1997) afirma que os(as) sujeitos(as) que formam a escola, não são apenas homens e mulheres, mas homens e mulheres de várias classes, raças, religiões e idades, tornando-a lugar de enfrentamento, mas também de questionamentos, possibilidades e solidariedades que podem provocar os arranjos mais diversos, perturbando a noção simplista e reduzida de "homem dominante versus mulher dominada" e a visão de que o conhecimento que ali se produz seja mera transposição. As escolas, inseridas em meio a comunidades e movimentos em disputa (como os feminismos), passaram a incorporar esta preocupação em disciplinas especializadas, mas principalmente nas abordagens mais gerais sobre democracia e demandas identitárias:

[...] a história recente do Brasil, marcada por violações dos direitos humanos no período ditatorial, como a de outros períodos mais remotos, com o cerceamento dos direitos de amplos segmentos da sociedade, está a exigir ações efetivas na identificação, preservação e difusão das memórias dos povos indígenas, dos afrodescendentes, das mulheres, dos idosos, dos gays, lésbicas, bissexuais, travestis, transgêneros (GLBTs), entre tantos outros grupos que buscam o empoderamento e se encontram em construção das identidades sociais e coletivas. (FERREIRA, 2007, p. 137)

Conforme Lúcia de Fátima Guerra Ferreira, a transformação da escola, não mais como mera reprodutora da desigualdade de gênero, passa pela produção de um conhecimento que chamamos aqui de "posicionado". Isso significa transformar o 


\section{HISTÓRIA}

Dossiê: Ensino de História, História das Mulheres e Desigualdades Sociais no Brasil

ensino de história, numa série de procedimentos e entendimentos que incluam a história das mulheres, em sua diversidade. Não se trata de acrescentar fatos a uma história masculina, no sentido lacunar, mas ampliar a compreensão dos processos históricos de forma mais complexa, trazendo à tona aquilo que permaneceu subterrâneo e invisibilizado: os micro-poderes, as subjetividades, as violências cotidianas, as táticas de lutas, entre outras tantas experiências que envolvem os gêneros.

Uma história pública das mulheres exige assumir uma postura mais ativa, dinâmica e criativa, levando em conta que instituições, práticas e concepções foram e são aprendidas e interiorizadas; tornando-se naturalizadas (ainda que sejam fatos culturais). A escola e o ensino de história que nela se pratica precisam ser pensados como partes importantes desse processo de construção, em busca de um aprendizado dialógico e continuado que penetre na vida dos(as) sujeitos(as) que a compõem, pelo qual possam constituir ou questionar suas "identidades escolarizadas" (LOURO, 1997, p.61), assim como o conhecimento histórico que nela circula.

O ensino de História e a história pública de e sobre mulheres

Neste texto, trabalhamos sob o entendimento de que o ensino de história das mulheres possa contribuir para questionar e romper com práticas escolares e conhecimentos históricos que ignoram ou tratam com indiferença as trajetórias, as subjetividades e as demandas coletivas femininas, no passado e no tempo presente, marcado por conquistas, opressões e por enfrentamentos necessários. Este posicionamento permitiria questionar estatísticas e números que também são construções sociais e têm significados; tratando de um passado inacabado, que se perpetua e produz efeitos sobre a vida social, inclusive de alunos(as) e professores(as).

Um ensino de história que coloca as mulheres como sujeitas de sua própria vivência, na relação com outras experiências, e em meio a estruturas capitalistas, racistas e sexistas, em diferentes tempos e espaços, contribui para pluralizar narrativas, rompendo com concepções lineares, homogêneas e pretensamente 


\section{HISTÓRIA}

Dossiê: Ensino de História, História das Mulheres e Desigualdades Sociais no Brasil

neutras de uma ciência e de formas de ensino que, na verdade, não o são. Se o gênero masculino hegemônico (branco, burguês, hetero e cisgênero) não necessita se esforçar para construir sua identidade individual ou coletiva e nem registrar sua história, uma vez que ela sempre esteve presente nos livros didáticos, nos monumentos e nos canais de comunicação midiáticos, o mesmo não se pode dizer das mulheres em sua diversidade.

No entanto, propor uma história pública das mulheres não se restringe aos procedimentos didáticos de transpor conteúdos e conceitos produzidos fora da escola pela Academia, por professores passivos para alunos desencantados. Lembramos o que Ricardo Santhiago discutiu sobre as dimensões da história pública, pensando sua prática para, com e pelo público (2016; 2018), o que nos convida a imaginar diferentes caminhos para nossa atuação como professores(as) preocupados(as) em ouvir, trocar ideias e nos reinventar junto aos(às) nossos(as) educandos(as). Em sala de aula, mais do que ensinarmos uma história traduzida e adaptada para os alunos e alunas, precisamos criar cenários participativos e mais democráticos, entendendo que eles e elas são apenas uma parte de um público que antecede e ultrapassa a sala de aula: as famílias, as comunidades, as redes de informação e as próprias experiências e memórias que cada um carrega. Esta atitude requer levar em conta as histórias que escapam pelas margens de toda narrativa única e pretensamente silenciadora do diverso; considerar as múltiplas vozes, trajetórias, saberes e existências que comportam as chamadas culturas escolares, pensando os currículos e as práticas pedagógicas como mutáveis, negociáveis e plurais, porque carregadas de disputas e desejos.

Ainda, Everardo Andrade e Nívea Andrade (2016) nos lembram que pensar numa história pública significa, também, questionar a ideia de determinação de lugares, de quem vive a história em relação a quem a registra; e de quem a registra em relação a quem a consome como audiência passiva. É necessário questionar os procedimentos que promovem omissões e apagamento das mulheres em operações historiográficas, em registros públicos e também na própria escola, num processo de encontro de diferentes saberes escolares, acadêmicos e cotidianos, que passam pelas memórias e pelas subjetividades femininas, pela ampliação de acesso a redes de saberes, criação de autorias e compartilhamentos coletivos; pelos usos de fontes 


\section{HISTÓRIA}

Dossiê: Ensino de História, História das Mulheres e Desigualdades Sociais no Brasil

e materiais não tradicionais; pelas apropriações de plataformas digitais, criando saberes em rede, cenários de inclusão e de enfrentamento de certa privatização masculina do saber.

Sônia Wanderley (2018) afirma que um(a) historiador(a)/professor(a) público(a) deve sempre ponderar sobre o seu lugar social na sociedade, sobre a sua responsabilidade diante dos agravamentos e injustiças de classe, de raça, de gênero e sexualidade, levando em conta os efeitos de suas escolhas ao ensinar. Avaliar e se responsabilizar eticamente pelo impacto educacional e social promovido pela postura praticada em aula significa desmontar um ser humano abstrato e apontar para as múltiplas existências, marcas identitárias e usos do passado que pretendem conservar ou reinventar lugares para as mulheres.

As histórias femininas, no entanto, não podem ser tratadas como tema à parte, como acessório de uma história masculina, ou reduzida a uma "grande história", em que a diversidade das mulheres seja sintetizada por uma trajetória única, europeia, branca, heterossexual e cisgênera. É preciso pensar histórias de mulheres indígenas, negras, LGBTQIA+s, sem heroificá-las e nem vitimizá-las como uma condição feminina essencialista, mas entendê-las enredadas nos processos históricos conflituosos, nas concretudes das existências individuais e coletivas, sempre em movimento de transformação.

As relações de gênero, assim como outros elementos que as constituem como sujeitas (como a etnia, a classe, a religião e a nacionalidade, entre tantos elementos) são também suscetíveis às mudanças históricas. Desta forma, ao considerarmos o gênero enquanto constituinte das identidades, passível de transformações ao longo do tempo, é inegável que esta categoria de análise tenha grande relevância no estudo da História, o que também inclui a prática da história escolar. Como afirmam Andrade e Andrade (2016, p.183), nas fronteiras de ensino de História, a comunidade escolar se movimenta em temporalidades disjuntivas, entre significações de passado e presente, entre conhecimentos historiográficos e memórias locais, entre histórias de vida e significações coletivas, dissolvendo polarizações e binarismos, ao mesmo tempo em que se apontam as diferenças na vida das mulheres na história e sua presença viva no espaço escolar, habitando o entrelugar em que se constituem os gêneros e suas relações. 


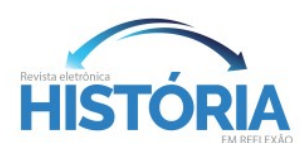

Dossiê: Ensino de História, História das Mulheres e Desigualdades Sociais no Brasil

Possibilidades do trabalho com o ensino de história pública das mulheres

Para trabalhar com a temática da história das mulheres na educação básica, numa dimensão de história pública, é necessário compreender a importância de estimular entre os alunos e as alunas a reflexão inicial que leve ao reconhecimento das mulheres enquanto sujeitas múltiplas cujas atuações foram marcadas por silenciamentos e também estereótipos na escrita da história e na história ensinada nas escolas. Essa dinâmica pode ser provocada, por exemplo, pelas narrativas das próprias alunas e professoras, em relação às expectativas que a sociedade tem sobre elas e as funções que desempenham cotidianamente, dividindo-se entre as dimensões públicas e privadas. ${ }^{7}$

A constituição de novos saberes e práticas escolares que contribuam para o reconhecimento das protagonistas da e na história deve-se fazer presente considerando que, ao compreender os currículos como construções políticas, artefatos culturais e documentos de identidades (SILVA, 1999) ${ }^{8}$, essas trajetórias possam entrar nas aulas de História como novos componentes curriculares transversais, por exemplo.

Considerando as especificidades de cada escola, com suas culturas escolares (SOUZA, 2005), objetivos e papéis próprios, agentes e saberes distintos de cada instituição, estimulamos que o trabalho docente ocorra com a reflexão permanente sobre suas práticas, partindo de questionamentos fundamentais e propostas que busquem metodologias, atividades e estratégias didáticas que estimulem e transformem os conteúdos estipulados na relação indissociável com os olhares sobre o protagonismo das mulheres.

Dessa forma, do nível prescritivo do currículo ao que efetivamente ocorre nas salas de aulas - o currículo vivido, como demonstra Ivor Goodson (1995) - os

\footnotetext{
${ }^{7}$ A dissertação de Viviane Alcântara Silva debate sobre essas e outras possibilidades do ensino de história das mulheres na sala de aula e apresenta uma série de oficinas desenvolvidas nas aulas de História que partiram das questões das violências domésticas noticiadas no país atualmente e as possibilidades de escrita das histórias das alunas como protagonistas de suas vidas. (SILVA, 2020).

${ }^{8}$ Optamos por não realizar, nesse artigo, uma análise sobre as políticas curriculares e as suas relações com a temática.
} 


\section{HISTÓRIA}

Dossiê: Ensino de História, História das Mulheres e Desigualdades Sociais no Brasil

professores e as professoras de História podem recorrer a uma multiplicidade de caminhos para ensinar a(s) história(s) das mulheres, ao buscar aproximar e relacionar aquele conteúdo do currículo formal aos saberes históricos escolares.

Na educação básica, atravessamos conteúdos que muitas vezes são pautados pelo recorte cronológico-linear que organiza os currículos da disciplina História. ${ }^{9} \mathrm{~A}$ partir das noções de tempo e temporalidades, especialmente propostas pelas observações de Reinhart Koselleck (2014), é possível ensinar, para além da linearidade, sobre as rupturas e descontinuidades nos processos sociais que envolvem sujeitos(as) na história e no tempo histórico (MIRANDA, 2012), tendo o recorte específico de gênero, classe e raça como eixos norteadores para contar outras histórias na sala de aula.

Na cultura do tempo de muitos livros didáticos (ALVIM, MIRANDA, 2008), há um esforço para a manutenção das representações de gênero e grupos étnico-raciais quase exclusivamente representados pela figura masculina, hetero e branca na história. Como afirma Cristiani Silva,

(...) a história das mulheres e, mesmo, as formulações sobre as diferenças e desigualdades de gênero, são, ainda, adendos da história geral, muitas vezes incorporadas e abrigadas sob o guarda-chuva das minorias étnicas, nacionais religiosas ou sexuais. (...) Textos e imagens presentes nos livros didáticos apresentam práticas sociais que configuram como dadas, situações que envolvem sexo e gênero, naturalizando assim homens e mulheres em papéis normativos, inscrevendo-os como sujeitos a-históricos que atuariam na história a partir de atitudes e condições socialmente preestabelecidas. De modo geral, os livros didáticos utilizados nas escolas trazem apropriações persistentes de imagens que informam um "mundo" ainda bastante masculino, de raça branca, adulto, cristão, heterossexual; de grupos que vivem em cidades, de sujeitos que estão trabalhando, que são magros, sadios, entre outros padrões hegemônicos. Nesse sentido, portanto, devem, cada vez mais, ser analisados como pedagogias que inscrevem modelos normativos. (SILVA, 2007, p. 229-230)

Diante do questionamento de certos modelos, é recorrente que professores(as) apontem sobre a necessidade de diversificar o uso dos materiais didáticos que auxiliem nas propostas, seja na própria problematização das ausências e

\footnotetext{
${ }^{9} \mathrm{O}$ trabalho de Diego Gomes Souza apresenta alternativas ao recorte cronológico-linear dos currículos de História e elenca as possibilidades de articular através do ensino temático e da transversalidade o ensino de História e diversidade sexual e de gênero na educação básica. (SOUZA, 2019).
} 


\section{HISTÓRIA}

Dossiê: Ensino de História, História das Mulheres e Desigualdades Sociais no Brasil

silenciamentos dos livros didáticos utilizados, como na busca por uma infinidade de materiais - livros, blogs, vídeos, podcasts, redes sociais e demais suportes que possam auxiliar nessa empreitada - assim como de fontes que tenham o registro das experiências femininas na história. O desafio desdobra-se em uma gama de possibilidades para a prática docente, a partir das alternativas que os usos de tecnologias disponibilizam (COSTA, 2015), ao mesmo tempo em que uma aparente ausência de fontes femininas se faz sentir devido à escrita majoritariamente masculina.

Esperando contribuir para pensarmos algumas práticas voltadas para uma história pública e suas relações com o ensino de história das mulheres, optamos por apontar, neste artigo, dois caminhos (entre muitos) que buscam valorizar suas ações e suas conquistas, além de combater todas as formas de discriminação e violência de gênero, e construir a igualdade de gênero nas escolas, especialmente nas aulas de História. Não se trata de ver aqui uma dimensão salvacionista da História, mas uma atitude provocadora de normalizações que levam à inação, à invisibilidade e ao conformismo.

O primeiro deles é pensar o ensino a partir da trajetória e história de vida das mulheres na história, por meio de narrativas biográficas ou autobiográficas escritas, publicadas e publicizadas. Desse modo, a utilização de biografias de mulheres diversas - em qualquer temporalidade recortada - pode ser um instrumento didáticopedagógico frutífero, tratando-se aqui de uma dimensão da história pública relacionada à divulgação e acesso a informações disponíveis, ampliando a audiência a fontes e narrativas. As abordagens biográficas e autobiográficas permitem evidenciar as trajetórias de vida desconhecidas, silenciadas e apagadas na História, a partir de documentos e materiais que se referem às histórias femininas, independente de seu registro. Isso significa afirmar que biografias e histórias de vida autobiográficas não se confundem, mas ambas são ricas dimensões para o trabalho em sala de aula.

Optamos aqui por sugerir o trabalho com mídias digitais, que não representam formas mais apropriadas ou melhores do que outros materiais. Pensamos na possibilidade do vasto material encontrado na internet que pode favorecer os(as) professores(as) que busquem mais informações sobre trajetórias femininas de vida 


\section{HISTÓRIA}

Dossiê: Ensino de História, História das Mulheres e Desigualdades Sociais no Brasil

para suas aulas. Vivemos num mundo em que a tecnologia digital favorece a multiplicidade de narrativas e de sujeitos(as) que se apropriam dela de acordo com uma série de intencionalidades, entre elas a busca de visibilidade e "empoderamento", este último entendido como processo de publicização de demandas e fortalecimento de lutas. No caso das mulheres, o material disponível pode contribuir muito para a pesquisa e reflexão em sala de aula, e mesmo fora dela.

Assim, buscando apontar algumas possibilidades de trabalhos com as narrativas de mulheres em rede, selecionamos alguns portais, como o do projeto Mulher 500 anos atrás dos Panos http://www.mulher500.org.br/biografia-de-mulheres/ que disponibiliza mais de 900 biografias de mulheres no Brasil, com informações sobre local e data de nascimento, principais atividades envolvidas, raça/etnia e a descrição da sua trajetória. O portal é organizado pela REDEH - Rede de Desenvolvimento Humano - uma organização não-governamental que tem como uma das missões, estimular a equidade de gênero, raça/etnia no âmbito das políticas públicas. A instituição tem um vasto acervo de pesquisa e livros publicados, com a perspectiva de contar as histórias das mulheres no Brasil.

Outros portais também disponibilizam fontes e acervos de pesquisa sobre mulheres em diferentes regiões do país. É o caso dos projetos desenvolvidos no Centro de Pesquisa e Documentação de História Contemporânea do Brasil (CPDOC), ligado à Fundação Getúlio Vargas (FGV). De fácil acesso, os portais exibem arquivos pessoais, como cartas, fotografias, registros, diários, fontes orais - com as entrevistas gravadas e disponibilizadas pelo portal - especialmente com o recorte da história política nacional, com a presença de mulheres https://cpdoc.fgv.br/acervo/historiaoral, além do Dicionário Histórico Biográfico Brasileiro https://cpdoc.fgv.br/acervo/dhbb com mais de 7 mil verbetes ligados também à história do Brasil pós-1930 e à biografia de mulheres nesse período. É um portal que permite acessar as biografias, mas também pesquisar fontes que facilitem processos de produção coletiva de conhecimento em sala de aula, sob os procedimentos do olhar historiográfico e dos saberes cotidianos.

Especialmente no que tange aos recortes étnico-raciais, além de publicações acadêmicas e trabalhos reconhecidos pela historiografia como fundamentais para a escrita da história das mulheres, muitas pesquisadoras e organizações atuam em 


\section{HISTÓRIA}

Dossiê: Ensino de História, História das Mulheres e Desigualdades Sociais no Brasil

diferentes frentes para a publicização das suas pesquisas, agindo em redes sociais e portais de notícias, com linguagens acessíveis e propostas de apresentação de diversas personagens negras e indígenas na história do Brasil, além da discussão central em torno das políticas e ações antirracistas. É o caso do catálogo Intelectuais Negras Visíveis, organizado por Giovana Xavier, disponível em PDF (https://www.intelectuaisnegras.com/) e o portal Geledés - Instituto da Mulher Negra (https://www.geledes.org.br/), fundado em 1988 por lideranças do movimento de mulheres negras, que articula pautas importantes para a visibilidade e empoderamento em diversas áreas, especialmente na comunicação.

Quanto às mulheres indígenas no Brasil, a Rede Grumin de Mulheres Indígenas (http://www.grumin.org.br/principal.htm) que atua desde 1997, na Baixada Fluminense, Rio de Janeiro, foi organizada por aldeadas e por moradoras das cidades que se apropriaram das mídias digitais para criar uma rede de comunicação indígena e apresentar suas versões para a história étnica e de gênero. O site do Conselho Indigenista Missionário (CIMI) (https://cimi.org.br/wp-content/uploads/2019/03/livromulheres-indigenas-tradicao.pdf) disponibiliza, também, material sobre a história de mulheres indígenas, assim como 0 site da ONU Mulheres (http://www.onumulheres.org.br/noticias/confira-algumas-historias-de-mulheresindigenas-do-brasil-no-dia-internacional-dos-povos-indigenas-do-mundo/). É possível estimular o acesso a essas plataformas e promover debates sobre a história indígena, do ponto de vista de experiências e de registros femininos e feministas.

Acervos como Memórias Reveladas (http://www.memoriasreveladas.gov.br/) ou aquele organizado pela Comissão Nacional da Verdade (http://cnv.memoriasreveladas.gov.br/) também apresentam uma série de narrativas de e sobre mulheres que lutaram contra a ditadura, algumas delas torturadas, exiladas e/ou assassinadas pelos agentes da repressão. As mídias digitais permitem, aqui, o acesso a livros e também a registro de testemunhos, de forma escrita ou a partir de entrevistas orais, que possibilitam conhecer e reconhecer a violência praticada contra elas durante o período autoritário (1964-84), assim como saber sobre suas lutas e as denúncias de desigualdade de gênero permeando desde sessões de tortura a relações com os homens em grupos armados. 


\section{HISTÓRIA}

Dossiê: Ensino de História, História das Mulheres e Desigualdades Sociais no Brasil

Em relação às mulheres LGBTQIA+, no Brasil, ainda há poucos acervos ou plataformas, mas sugerimos que os(as) alunos(as) possam realizar pesquisas no acervo de mídias digitais do Museu da Diversidade Sexual (http://www.mds.org.br/), com algumas atividades culturais e partes das exposições voltadas para as temáticas da cidadania, preconceito, direitos humanos, orientação sexual, identidade e expressão de gênero; ou ainda conhecer o acervo Close (https://www.facebook.com/close.historia/), organizado por Benito Schmidt, num trabalho de história pública com a comunidade LGBTQIA+ do Rio Grande do Sul, por meio de histórias orais e documentação relativa ao movimento.

Isso representa um desafio aos(às) docentes que se veem diante de muitas outras narrativas, em rede e fora da escola, que exige por parte deles(as) novos saberes tecnológicos e novas posturas para lidar com a não exclusividade do saber histórico. Como apontado por Miriam Hermeto e Rodrigo Ferreira,

reside nesse ponto boa parte da importância atribuída aos professores e professoras, na sala de aula, nos debates sobre história pública. Em tempos nos quais a internet alterou substancialmente a forma de acesso à informação, docentes precisam assumir a responsabilidade de contribuir para o aprendizado dos modos de usar a internet para fins educativos, levando os estudantes a compreenderem que as volumosas informações, disponíveis a um clique do computador ou do celular, não podem ser confundidas com conhecimento. (HERMETO, FERREIRA, 2018, p. 11)

É preciso ficar claro que o ensino de história voltado à história pública não se resume a acessar plataformas digitais ou demais mídias para obter mais informações. Não se trata de uma questão quantitativa, correndo-se o risco de cair no perigo do excesso de narrativas. A tecnologia de divulgação e a ampliação de acessos são apenas procedimentos que podem ou não estar relacionados com a história pública. A ausência do compromisso em criar cenários participativos e dialógicos em sala de aula, em que esses acervos e fontes sejam submetidos à análise cuidadosa, a partir de conceitos e de conteúdos também da ciência História, pode levar a equívocos e à confusão entre conhecimento histórico e a opinião por excesso de dados. Livros biográficos impressos, vídeos, fotografias ou documentos digitais/ou digitalizados que tratam das biografias de mulheres precisam ser submetidos ao debate e os(as) professor(as) devem ser os(as) provocadores(as) e mediadores(as), para que se 


\section{HISTÓRIA}

Dossiê: Ensino de História, História das Mulheres e Desigualdades Sociais no Brasil perceba que todos os materiais são passíveis de autoria, de usos e abusos em determinado tempo e por diversos interesses, e que as maneiras com que estes são manuseados produzem efeitos sociais e leituras diferentes sobre o passado e o presente (e, também, perspectivas de futuros públicos). Informações comunicadas e transmitidas não significam, necessariamente que sejam compartilhadas, pois a divulgação deve ser sempre acompanhada de reflexão coletiva, mediada pelo encontro entre saberes locais, saberes acadêmicos e saberes em rede.

Outro caminho sugerido para o ensino de história das mulheres parte da história de vida, a partir de fontes subjetivas e do universo privado, múltiplo e rico de suas vivências. Fotografias, livros de receitas, diários, objetos de intimidade feminina, materiais que remetem às suas profissões, assim como narrativas orais no tempo presente, produzidas pelo diálogo, podem entrar na sala de aula como estratégias do processo de ensino-aprendizagem, numa dimensão de história pública, agora pensando não apenas a divulgação e o acesso ao conhecimento, mas o debate, a seleção, a produção e a elaboração de compartilhamento pelo público entendido como ativo e participante de todo o processo (no caso, aluno/as e toda a comunidade escolar ou externa).

Os procedimentos de história oral de vida de mulheres na sala de aula é um dos recursos para que professores(as) mobilizem alunos(as) e, em conjunto, protagonizem o reconhecimento de suas trajetórias de vida, na medida em que estimulem a sensibilidade e a ética da escuta. Dessa maneira, os(as) docentes contribuirão para a desmistificação das desigualdades naturalizadas por relações de dominação que se reproduzem nas famílias e na escola, e para a valorização das diferenças que dão significado às suas vidas (LOURO, 1997).

Os(as) professores(as) devem atuar como provocadores(as), trazendo para o contexto de ensino a sua própria trajetória de formação acadêmica, as histórias de seus (suas) alunos(as), de seus(suas) familiares e de funcionárias próximas aos(às) estudantes, como diretoras, coordenadoras, funcionárias da limpeza e da cantina ou, ainda, mulheres conhecidas no bairro, a quem possam convidar e entrevistar. Devem estimulá-los(as), fazendo-lhes perguntas sobre os diferentes tempos (do vivido, do registrado e dos usos políticos e sociais), acerca dos(as) sujeitos(as) envolvidos(as) nas evidências e nas omissões sobre as experiências femininas, assim como sobre 


\section{HISTÓRIA}

Dossiê: Ensino de História, História das Mulheres e Desigualdades Sociais no Brasil

os significados das narrativas: quem narra trata sobre que conteúdo? Mais do que isso, seleciona o que para narrar? Para que, para quem e como narra a sua história? As mulheres tratam dos mesmos temas e ações, relatam e registram da mesma forma que os homens? Se o fazem de forma diferente, por que o fazem? As mulheres relatam e registram as mesmas histórias entre si?

Ao utilizar os materiais, portais e/ou publicações diversas para articular no espaço educativo as discussões sobre gênero e a produção das narrativas das mulheres no tempo presente, ligadas ao contexto de vida dos alunos e alunas, dialogamos com as propostas da história pública, que pretende desenvolver em processo de colaboração (MEIHY, 2005) e autoria compartilhada (FRISH, 2016) a produção e a divulgação do conhecimento histórico de forma mais democrática.

Nesse processo, também importantes documentos privados e do cotidiano das mulheres podem ser coletados e analisados: fotografias, diários, livros de receitas, rezas e orações guardadas, materiais das casas que remetem às lembranças familiares, assim como outros objetos biográficos (que também dizem respeito ao mundo do trabalho e à sua vida pública), que contribuem para estimular relatos orais. Antecedendo as entrevistas, os acervos de narrativas orais como o do Museu da Pessoa (https://www.museudapessoa.org/pt/home) podem ser acessados pelos(as) estudantes e trabalhados em sala para se estimular a escuta de histórias de mulheres migrantes, negras, indígenas, operárias e contribuir para que elaborem pequenos projetos de escuta de histórias orais de vida.

Um processo importante para promover estranhamentos e identificações seria organizar projetos voltados às histórias de vida de mulheres negras e LGBTQIA+, que façam parte da própria cidade, ou que pertençam à comunidade escolar, como professores(as), alunos(as) e funcionários(as). Muitas vezes os(as) alunos(as) convivem com familiares e amigos(as) que poderiam contribuir com seus relatos, rompendo estereótipos e evidenciando posturas racistas, heteronormativas e cisgêneras naturalizadas no cotidiano das famílias, dos grupos de amigos ou no espaço escolar. Seria uma oportunidade para reconhecer práticas e discursos que produzem estigmas e registrar histórias, fazer comparações com outras temporalidades e espaços e aprender sobre permanências e mudanças, inserindo as histórias pessoais em contextos sociais. A série de entrevistas poderia promover, 


\section{HISTÓRIA}

Dossiê: Ensino de História, História das Mulheres e Desigualdades Sociais no Brasil ainda, um trabalho coletivo de formação de acervos de história oral de mulheres pela comunidade escolar.

Um ensino de história inclusivo e em movimento

Como todo planejamento de ensino, para a realização das propostas que apresentamos é fundamental partir do conhecimento prévio das turmas escolares, da comunidade ao redor, dos saberes históricos adquiridos, dos conceitos e do posicionamento quanto ao que pretendemos provocar e (des)construir. As diferentes linguagens midiáticas utilizadas como ferramentas de ensino e divulgação - como os próprios portais sugeridos, além de vídeos, músicas, programas de rádio e podcasts - assim como o processo de escuta das narrativas orais a serem selecionadas com os(as) alunos(as), devem passar pelo debate sobre histórias, disputas e silenciamentos nas relações de gênero.

Independente do produto a ser gerado, é importante que se entenda que a história pública se desenvolve no processo inclusivo de produção e de compartilhamento de saberes em sala de aula. Os projetos ou resultados dos trabalhos devem ser constantemente elaborados de forma coletiva, em diálogo, para que se compreenda o porquê da opção por uma (ou muitas) história das mulheres. Os debates poderão ser divulgados por meio de livros coletivos, história em quadrinhos, produção de jogos históricos, literatura de cordel, músicas e, ainda, disponibilizados em redes sociais específicas para esse fim e com as contas administradas pelos próprios alunos e alunas. O mais importante, no entanto, é que as relações de gênero em sala de aula sejam afetadas pela reflexão e pelo entendimento histórico ali proporcionado.

Partimos do pressuposto de que as propostas de metodologias de ensino de História que valorizam a problematização, a análise e a crítica da realidade concebem que os alunos e alunas sejam sujeitos(as) produtores(as) de história e conhecimento e que sejam por eles transformados(as). Assim, como Ricardo Santhiago $(2016 ; 2018)$ nos provocou a pensar a história pública, consideramos que ela tem sido uma 


\section{HISTÓRIA}

Dossiê: Ensino de História, História das Mulheres e Desigualdades Sociais no Brasil demanda do próprio ensino de História acerca das linguagens, da participação e dos recursos para que os saberes históricos se amplifiquem.

O trabalho com histórias de mulheres, em especial na perspectiva da história pública, pode proporcionar processos de aprendizado junto aos(as) estudantes que se convertam em exercícios empáticos, dentro e fora de sala de aula. Este tipo de prática, que envolve diretamente os(as) alunos(as) e docentes no acesso, na seleção e na elaboração de fontes, de conhecimento histórico e de formas de divulgação de uma história feminina (cujo conceito também deve ser problematizado como não essencialista e construído), permite pensar formas de devolução à comunidade. Exposições, mesas redondas, rodas de conversas, produção de museus comunitários e vídeos, disponibilizados em plataformas digitais ou em encontros presenciais devem trazer a vida das mulheres para dentro do ensino de história e articular entre a comunidade escolar discussões sobre os dados estatísticos e as relações de desigualdade de gênero.

No contexto atual da sociedade brasileira contemporânea, o ensino de história posicionado tem potencialidades para alterar as tristes estatísticas apresentadas no início desse texto e também problematizar as relações de poder existentes, por meio do estudo do passado e das relações com o presente, do questionamento das hierarquias sociais e de narrativas hegemônicas de gênero, de classe e de raça constituídas historicamente no país.

\section{Referências}

ALMEIDA, Juniele Rabêlo de; ROVAI, Marta Gouveia de Oliveira (Org). Introdução à história pública. São Paulo: Letra e Voz, 2011.

ANDRADE, Everardo; ANDRADE, Nívea. História pública e educação: tecendo uma conversa. experimentando uma tessitura In: MAUAD, Ana M.; ALMEIDA, Juniele R.; SANTHIAGO, Ricardo. História Pública no Brasil: sentidos e itinerários. São Paulo: Letra e Voz, 2016, p..

ALVIM, Yara Cristina; MIRANDA, Sonia Regina. Sobre a cultura do tempo e o livro didático de História. História \& Ensino, v. 14, p. 115-132, 2008.

BARTHOLO, Letícia; PASSOS, Luana; FONTOURA, Natália. Bolsa família, autonomia feminina e equidade de gênero: o que indicam as pesquisas nacionais? Instituto de Pesquisa Econômica Aplicada.- Brasília : Rio de Janeiro : 


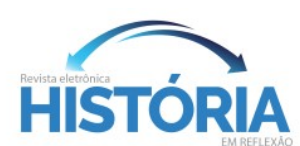

Dossiê: Ensino de História, História das Mulheres e Desigualdades Sociais no Brasil

Ipea , 2017. - Disponível em:

http://repositorio.ipea.gov.br/bitstream/11058/8051/1/td 2331.PDF - acesso em 10 jun 2020.

BENEVIDES, Bruna G.; NOGUEIRA, Sayonara N. Bonfim (org). Dossiê dos assassinatos e da violência contra travestis e transexuais brasileiras em 2019. São Paulo: Expressão Popular, ANTRA, IBTE, 2020. Disponível em: https://antrabrasil.files.wordpress.com/2020/01/dossic3aa-dos-assassinatos-e-daviolc3aancia-contra-pessoas-trans-em-2019.pdf. Acesso em: 20 fev. 2020.

BITTENCOURT, Circe. Ensino de História: fundamentos e métodos. São Paulo: Cortez, 2004.

BONDÍA, Jorge Larrosa. Notas sobre a experiência e o saber da experiência. Revista Brasileira de Educação. n¹9, p. 20-28, jan/fev/mar/abr, 2002.

BRASIL. Com sete senadoras eleitas, bancada feminina no Senado não cresce. Agência Senado. Brasília. Disponível em: https://www12.senado.leg.br/noticias/materias/2018/10/08/com-sete-senadoraseleitas-bancada-feminina-no-senado-nao-cresce - Acesso em 12 dez 2019.

.Balanço anual: Ligue 180 recebe mais de 92 mil denúncias de violações contra mulheres. Brasília: Ministério dos Direitos Humanos, 2019. Disponível em https://www.mdh.gov.br/todas-as-noticias/2019/agosto/balanco-anual-ligue-180recebe-mais-de-92-mil-denuncias-de-violacoes-contra-mulheres. Acessado em 08/09/2019.

COLLING, Ana Maria; TEDESCHI. O ensino de história e os estudos de gênero na historiografia brasileira. História e Perspectivas, Uberlândia (53), p. 295-314, jan./jun. 2015.

CARVALHO, Bruno Leal; TEIXEIRA, Ana Paula T. História Pública e divulgação de história. São Paulo: Letra e Voz, 2019.

COSTA, Suely Gomes. Gênero e História. In: ABREU, Martha; SOIHET, Rachel (org.). Ensino de História: conceitos, temáticas e metodologia. Rio de Janeiro: Casa da Palavra, 2003.

FERREIRA, Rodrigo de Almeida. O cinema na história pública: balanço do cenário brasileiro (2011-2015) In: MAUAD, Ana M.; ALMEIDA, Juniele R.; SANTHIAGO, Ricardo. História Pública no Brasil: sentidos e itinerários. São Paulo: Letra e Voz, 2016. p.133-147.

Quais as relações entre a história pública e o ensino de história? In: BORGES, Viviane Trindade; MAUAD, Ana Maria; SANTHIAGO, Ricardo (org.) Que história pública queremos? What public history do we want? São Paulo: Letra e Voz, 2018. 


\section{HISTÓRIA}

Dossiê: Ensino de História, História das Mulheres e Desigualdades Sociais no Brasil

FERREIRA, Lúcia de Fátima Guerra et al. Educação em Direitos Humanos:

Fundamentos teórico-metodológicos. João Pessoa: Ed. Universitária, 2007.

FONSECA, Thaís Nivia de Lima. História e Ensino de História. Belo Horizonte: Autêntica, 2006.

FRISH, Michael. A história pública não é uma via de mão única ou De $A$ Shared Authority à cozinha digital, ou vice versa In: SANTHIAGO, Ricardo; MAUAD, Ana M; ALMEIDA, Juniele R. (org.).História pública no Brasil: sentidos e itinerários. São Paulo: Letra e Voz, 2016, p.57-70.

GOMES, Nilma Lima. Relações étnico-raciais, educação e descolonização dos currículos. Currículo sem Fronteiras, v.12, n.1, p. 98-109, jan/abr 2012.

GOODSON, Ivor. Currículo: teoria e história. Petrópolis: Vozes, 1995.

HERMETO, Miriam; FERREIRA, Rodrigo de Almeida. Ensino de História e História Pública: um começo de conversa. Apresentação. Revista História Hoje, vol. 8, $\mathrm{n}^{\circ}$ 15, p. 5-16, 2018.

KOSELLECK, Reinhart. Estratos do Tempo: estudos sobre a História. Rio de Janeiro: Contraponto, Editora PUC-RJ, 2014.

LEITE, Juçara. Fazendo gênero na história ensinada: uma visão além da (in)visibilidade. In: Secretaria de Educação Básica. Coleção Explorando o Ensino História, Ensino Fundamental. v. 21. 2010.

LIDDINGTON, Jill. O que é História Pública: os públicos e seus passados. In: ALMEIDA, Juniele Rabêlo de; ROVAI, Marta Gouveia de Oliveira (org). Introdução à história pública. São Paulo: Letra e Voz, 2011, p.31-50.

LOURO, Guacira Lopes. Gênero, sexualidade e educação: uma perspectiva pósestruturalista Petrópolis: Vozes, 1997.

MEIHY, José Carlos S. B. Manual de História Oral. São Paulo: Loyola, 2005.

MIRANDA, Sonia Regina. Aprender e ensinar o tempo histórico em tempos de incertezas: reflexões e desafios para o professor de história. In: GONÇALVES, Márcia de Almeida; ROCHA, Helenice; REZNIK, Luis; MONTEIRO, Ana Maria (org.). Qual o valor da história hoje? Rio de Janeiro: Editora da FGV, 2012, p. 241-262.

PEREIRA, Nilton Mullet; SEFFNER, Fernando. Ensino de História: passado vivo e educação em questões sensíveis. História Hoje, v. 7, n. 13, p. 14-33, 2018.

PINSKY, Carla B. (org.). Gênero. In: Novos temas nas aulas de história. São Paulo: Contexto, 2013. 


\section{HISTÓRIA}

Dossiê: Ensino de História, História das Mulheres e Desigualdades Sociais no Brasil

ROCHA, Helenice; MAGALHÃES, Marcelo; GONTIJO, Rebeca (org.) A escrita da história escolar: memória e historiografia. Rio de Janeiro: Ed. FGV, 2009.

SANTHIAGO, Ricardo. Duas palavras, muitos significados: alguns comentários sobre a história pública no Brasil In: SANTHIAGO, Ricardo; MAUAD, Ana M;

ALMEIDA, Juniele R. (org.) História pública no Brasil: sentidos e itinerários. São Paulo: Letra e Voz, 2016.

SILVA, Cristiani Bereta da. O saber histórico escolar sobre as mulheres e relações de gênero nos livros didáticos de história. Caderno Espaço feminino, v. 17, p. 219246, 2007.

SILVA, Tomaz Tadeu da. Documentos de identidade: uma introdução às teorias do currículo. Belo Horizonte: Autêntica, 1999.

SILVA, Viviane Alcantara. História das Mulheres na sala de aula. Dissertação (Mestrado Profissional em Ensino de História). Universidade Federal Fluminense, Niterói (RJ), 2020.

SOUZA, Diego Gomes. Ensino de História e diversidade sexual e de gênero: articulando direitos humanos, transversalidade e ensino temático. In: Anais

Eletrônicos do I Congresso Nacional do ProfHistória. Salvador (BA) IAT, 2019, pp. 1-10. Disponível em:

$<$ https://www.even3.com.br/anais/congressonacionalprofhistoria/174697-ensino-dehistoria-e-diversidade-sexual-e-de-genero--articulando-direitos-humanostransversalidade-e-ensino-tema/>, Acesso em 31 jul. 2020.

SOUZA, Rosa Fátima de. Cultura escolar e currículo: aproximações e inflexões nas pesquisas históricas sobre conhecimentos e práticas escolares. In: TARDIF, Maurice; LESSARD, Claude. O trabalho docente: elementos para uma teoria da docência como profissão de interações humanas. Petrópolis: Vozes, 2005.

WANDERLEY, Sônia. Didática da História escolar: um debate sobre o caráter público da História ensinada In: RABELO, Juniele R.; MENESES, Sônia (org). História Pública em debate: patrimônio, educação e mediações do passado. São Paulo: Letra e Voz, 2018, p.95-108. 